\title{
Total Antioxidant Capacity and Lipid Peroxidation Status in Cervical Cancer Patients Compared with Women Without Cervical Cancer in Bangladesh
}

\author{
Taslima Nigar $^{1} \cdot$ Annekathryn Goodman $^{2}$ (D) Shahana Pervin ${ }^{1}$
}

Received: 24 March 2021 / Revised: 16 May 2021 / Accepted: 3 June 2021 / Published online: 6 July 2021

(c) The Author(s) 2021

\begin{abstract}
Purpose Over the past several decades, research has suggested reactive oxygen species act as cofactors for cervical cancer development. The aim of this study is to evaluate the antioxidant and lipid peroxidation status in cervical cancer patients in Bangladesh.

Methods From December 2017 to 2018, a cross-sectional observational study was conducted on 50 cervical cancer patients and 50 controls. Plasma levels of lipid peroxidation and total antioxidant capacity were measured. The Student's $t$ test was used for statistical analysis. $P$ values less than 0.05 were taken as a level of significance.

Results There was a significant reduction in total antioxidant levels in patients with cervical cancer, $972.77 \pm 244.22 \mathrm{SD}$ $\mu \mathrm{mol}$ equivalent to ascorbic acid/L, compared to normal controls, $1720.13 \pm 150.81 \mathrm{SD} \mu \mathrm{mol}$ equivalent to ascorbic acid/ $\mathrm{L}(P<0.001)$. Levels of lipid peroxidation were found to be significantly higher in cervical cancer, $7.49 \pm 2.13 \mathrm{SD} \mu \mathrm{mol} /$ $\mathrm{L}$, than in women without cervical cancer, $3.28 \pm 0.58 \mathrm{SD} \mu \mathrm{mol} / \mathrm{L}(P<0.001)$. The cervical cancer patients had significantly higher levels of oxidative stress index $(0.83 \pm 0.31)$ in comparison to controls $(0.19 \pm 0.04)(P<0.001)$.

Conclusion There was an increased oxidative stress index due to imbalance between lipid peroxidation generation and total antioxidant capacity in cervical cancer patients. Further studies are needed to explore the role of oxidative stress as a cofactor for cervical carcinogenesis.
\end{abstract}

Keywords Cervical cancer $\cdot$ Lipid peroxidation $\cdot$ Total antioxidant capacity $\cdot$ Oxidative stress index $\cdot$ Malondialdehyde (MDA)

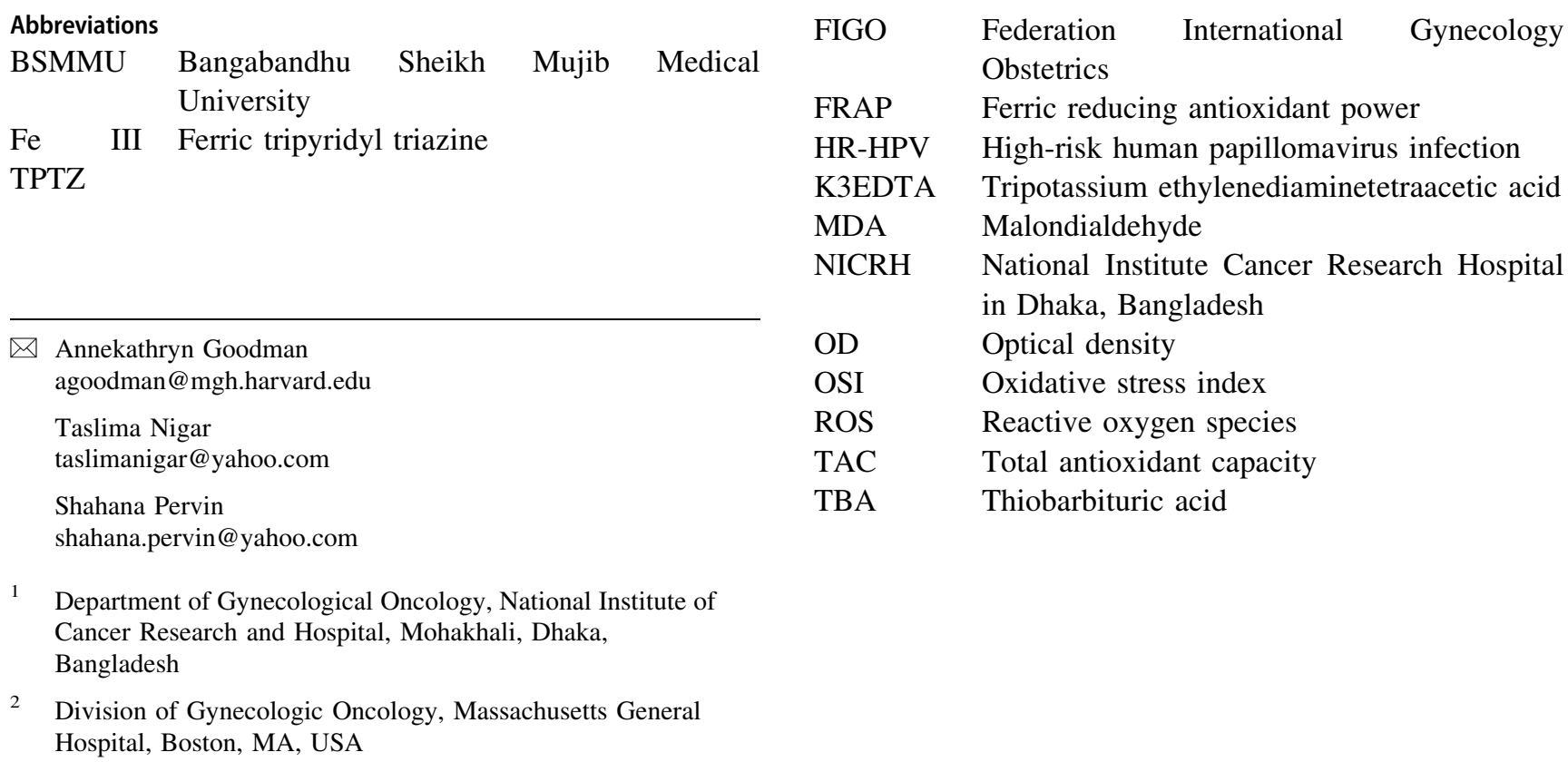




\section{Introduction}

Cervical cancer is a major public health problem worldwide. Cervical cancer ranks as the second leading cause of female cancer and the second most common female cancer in women aged 15-44 years in Bangladesh. The estimated age-standardized incidence and mortality rates of cervical cancer were approximately 10.6 and 7.1 per 100,000 women, respectively, in 2018. In the same year, about 8068 new cervical cancer cases and 5214 deaths in Bangladesh were recorded [1]. These rates may significantly underestimate the true rates of cervical cancer in Bangladesh, which does not currently have a national cancer data registry [2].

Human papilloma virus (HPV) DNA is found in $99 \%$ of invasive cervical cancers worldwide [3, 4]. Infection with a high-risk (HR-HPV) human papilloma virus subtype typically lasts from 12 to 18 months and is eventually cleared by the immune system [5]. However, approximately $10 \%$ of women do not clear HR-HPV infections, resulting in a persistent infection. The main consequence of persistent infection with HR-HPV is the progression of precancerous lesions to cancer [6].

Integration of HPV genomes into the host chromosomes and the aberrant expression of viral oncogenes play central etiologic roles for the development of cervical cancer [7]. It is hypothesized that HPV-induced inflammation generates reactive oxygen species (ROS), which might create DNA strand breaks. These DNA strand breaks may enable HPVDNA integration into human genome. In this way, the intercalated HPV-DNA can lead to uncontrolled cell growth and carcinogenesis [8]. Along with viral oncogene expression, other cofactors are needed for cancer to occur. A pooled analysis study for the International Agency for Research on Cancer Multicenter Cervical Cancer Study Group found a statistically significant association of cervical carcinoma with high parity [9]. This may correlate with increased and unprotected exposures to HR-HPV. The influence of cofactors such as smoking, inflammation, infections, immunodeficiency states and malnutrition is well documented [10]. Environmental exposures such as tobacco are important. One study showed that women who never smoke but were exposed to smoking had a $73 \%$ increase in risk of cervical cancer compared with non-exposed women $\quad(\mathrm{OR}=1.73, \quad 95 \% \quad \mathrm{CI}=1.35-2.21$, $P<0.001)$ [11]. The mechanism of promoting carcinogenesis by some of these cofactors may be through the increase of free radicals [12].

Reactive oxygen radicals (ROSs) are highly reactive species that have been implicated in the initiation and progression of carcinogenesis through DNA damage, genomic instability, tumor suppressor gene reduction, increased expression of proto-oncogenes and alterations to immunological defense mechanisms [13]. Mammals have complex antioxidant strategies to minimize the noxious effects of ROS. Under normal conditions, the toxic effects of ROS upon the cells are neutralized to a large extent by a cascade of antioxidant defenses. Imbalance between ROS and antioxidants produces oxidative stress [14].

In humans, direct measurement of oxidative stress is difficult as the reactive oxygen species are extremely shortlived. However, the products of the reactive oxygen species-induced lipid peroxidation can be measured and can provide an indirect measure of oxidative stress $[15,16]$. The combination of different antioxidants provides greater protection than any compound alone. The plasma total antioxidant capacity (TAC) is regarded as more representative of the in vivo balance between oxidizing species and antioxidant compounds (both the known and unknown, and the measurable and not measurable) than the concentration of single, selected antioxidants [17]. The role of oxidative stress has been studied in relation to HPV-related cervical carcinogenesis [14]. The current study investigated the total antioxidant capacity and lipid peroxidation status in cervical cancer patients compared to controls in Bangladesh.

\section{Materials and Methods}

A cross-sectional observational study was conducted in the Department of Gynaecological Oncology of the National Institute of Cancer Research and Hospital (NICRH), in Mohakhali, Dhaka, Bangladesh, from December 2017 to 2018. Fifty patients with a diagnosis of cervical cancer were taken as cases. The control group was recruited from the outpatient department and included fifty women without cervical cancer as documented by either by visual inspection with acetic acid (VIA) negative test or cervical cytology negative. The control group was age-matched with the participants carrying a diagnosis of cervical cancer. The sampling technique used the purposive non-random sampling method [18]. The inclusion criteria consisted of participants between the ages of 35 and 55 years, histopathologically confirmed cervical cancer, no prior pelvic radiation, chemotherapy and pelvic surgery. Exclusion criteria encompassed patients above 55 years of age or below the age of 35 years, known secondary malignancies, immunocompromised due to medical comorbidities, diabetes mellitus, hypertension or severe anemia. The age restriction was added to reduce possible variations in immune function that may alter oxidative function [19]. 


\section{Study Procedure}

The research protocol was approved by the Ethical Review Committee of NICRH. The aims and objectives of the study along with its procedure, methods, risks and benefits of this study were explained to each participant in easily understandable local language, and written informed consent was taken from each patient. All information and records were kept confidential and separate from the participants' medical records.

Using standard aseptic precautions, $5 \mathrm{ml}$ of venous blood from antecubital vein was taken in a Stoppard polyethylene tube containing $60 \mu \mathrm{L} \mathrm{k}_{3}$ EDTA anticoagulant (tripotassium ethylenediaminetetraacetic acid). After centrifugation at $3000 \mathrm{rpm}$ for $10 \mathrm{~min}$, plasma was separated and stored at $-40{ }^{\circ} \mathrm{C}$ until analysis was performed at the pharmacology research laboratory of Bangabandhu Sheikh Mujib Medical University (BSMMU). Data were collected using a pre-designed, approved data collection sheet.

\section{Biochemical Analysis}

Total antioxidant activity was measured by ferric reducing antioxidant power (FRAP) assay [20]. At low pH, reduction of ferric tripyridyl triazine (Fe III TPTZ) complex to the ferrous form produces an intense blue color. The change in color is directly related to the total reducing power of the electron-donating antioxidants present in the reaction mixture. The absorbance optical density (OD) of color changes can be monitored by the spectrophotometric method at $593 \mathrm{~nm}$. Plasma samples $(100 \mu \mathrm{l})$ were mixed with $3 \mathrm{ml}$ of working FRAP reagent and vortexed. After measuring the $\mathrm{OD}$ at $0 \mathrm{~min}$, the samples were placed at $37{ }^{\circ} \mathrm{C}$ in water bath and absorbance was again measured after 4 min. Ascorbic acid standards (M.W 176.13) $(100-1000 \mu \mathrm{M})$ were processed in the same way. Plasma lipid peroxidation was estimated by measuring malondialdehyde (MDA) as previously described [21]. The end product of lipid peroxidation (MDA) reacting with thiobarbituric acid (TBA) produced a color reactive substance which was measured by spectrophotometrically at $530 \mathrm{~nm}$.

\section{Statistical Analysis}

The mean of two groups was compared using the Student $t$ test. $P$ values $<0.05$ were considered statistically significant. Statistical analysis was performed by using software devised with SPSS for Windows version 23.

\section{Results}

Among the 100 participants, half of the participants were cervical cancer patients. The demographics and socioeconomic characteristics of the patients were similar to women with cervical cancer in other countries (Table 1). In this study, the mean age of cervical cancer patients was $47.4 \pm 12.2$ years which is similar to the mean age of $44.9 \pm 7.89$ years found by other investigators [22]. The mean age of menarche of cancer patients was $12.5 \pm 0.63$ SD years, and in control group it was $13.8 \pm 1.6$ SD years. This observation was in consistent with the finding of others [23]. They also found the ages of menarche in cancer patient and control were 13.7 and 13.9 years, respectively. In the present study, more than $86 \%$ of cancer patients were below the age of 18 years at marriage. Our observation agreed with others who found age at marriage (HR $=0.9$, more than 18 vs less) [24]. In our study 54\% of the cancer patients were grand multiparous and $44 \%$ were multiparous. Regarding occupations, $84 \%$ of cancer patients were housewives and $16 \%$ worked outside the home. This observation was in agreement with other reports who found no significant association with incidence of cervical cancer with respect of occupation [25]. In our study, $64 \%$ of cancer patients and $42 \%$ of control women were oral contraceptive pill users. In the present study, no active smokers were found in either case or control groups. In the cancer group $84 \%$ and in the control group 52\% were exposed to tobacco through their husbands or employment and were categorized as passive smokers.

Of the fifty women with cervical cancer, nine had adenocarcinomas and the remainder (82\%) had invasive squamous cell cancers. Ninety-four percent of the cancers were grade 3 . The majority of women presented with Stage IIIb cancers $(48 \%)$, and $14 \%$ and $38 \%$ of the cases carried diagnoses of Stage Ib3 and Stage IIb cancers, respectively.

Table 2 shows the lipid peroxidation level and the total antioxidant capacity of women with cervical cancer compared to controls. In cervical cancer patients, the mean lipid peroxidation product (MDA) level was $7.49 \pm 2.13$ $\mathrm{SD} \mu \mathrm{mol} / \mathrm{L}$ and in the control group it was $3.28 \pm 0.58 \mathrm{SD}$ $\mu \mathrm{mol} / \mathrm{L}$. The difference between the two means was statistically significant $(P<0.001)$. In cervical cancer patients, the mean total antioxidant capacity (TAC) level was $972.77 \pm 244.22 \mathrm{SD} \mu$ mol equivalent to ascorbic acid/ $\mathrm{L}$ and in the control group it was $1720.13 \pm 150.81 \mathrm{SD}$ $\mu \mathrm{mol}$ equivalent to ascorbic $\mathrm{acid} / \mathrm{L}$. The difference between the two means was statistically significant $(P<0.001)$. In cervical cancer patients, the mean oxidative stress index (OSI) calculated by MDA/TAC $\times 100$ was $0.83 \pm 0.31 \mathrm{SD}$ in cancer patients and $0.19 \pm 0.04 \mathrm{SD}$ in the comparison group. The difference between the two 

characteristics of participants
Table 1 Demographics

\begin{tabular}{lll}
\hline Variable & Cervical cancer $N=50(\%)$ & Control $N=50(\%)$ \\
\hline Age (year) & $47 \pm 12.2$ & $46.3 \pm 12$ \\
Age of menarche (year) & $12.5 \pm 0.63$ & $13.8 \pm 1.6$ \\
Age of marriage (years) & & \\
$<14$ & $20(40 \%)$ & $15(30 \%)$ \\
$15-17$ & $23(46)$ & $25(50)$ \\
$>18$ & $7(14)$ & $10(20)$ \\
Parity & & \\
Primiparous & $1(2 \%)$ & $5(10 \%)$ \\
Multiparous & $22(44)$ & $40(80)$ \\
Grand multiparous & $27(54)$ & $5(10)$ \\
Occupation & & $37(74 \%)$ \\
Housewife & $42(84 \%)$ & $13(26)$ \\
Service holder & $8(16)$ & $21(42 \%)$ \\
Oral contraceptive & & $29(58)$ \\
User & $32(64 \%)$ & $26(52 \%)$ \\
Non-user & $18(36)$ & $24(48)$ \\
Smoking & $42(84 \%)$ & \\
Passive smoking & $8(16)$ & \\
Non smoker & & \\
\hline & &
\end{tabular}

Table 2 Comparison of lipid peroxidation (MDA) and total antioxidant capacity (TAC) level for women with cervical cancer versus women without cervical cancer (control)

\begin{tabular}{lcc}
\hline & $\begin{array}{l}\text { Lipid peroxidation level } \\
\text { Mean } \pm \text { SD }\end{array}$ & $\begin{array}{l}\text { Total antioxidant capacity } \\
\text { Mean } \pm \text { SD }\end{array}$ \\
\hline Cervical cancer $(N=50)$ & $7.49 \pm 2.13$ & $972.77 \pm 244.22$ \\
Control $(N=50)$ & $3.28 \pm 0.58$ & $1720.13 \pm 150.81$ \\
$P$ value & $<0.001$ & 0.001 \\
\hline
\end{tabular}

TAC ( $\mu$ mol equivalent to ascorbic acid/L); Student's $t$ test is done to measure the level of significance $S D$ standard deviation means was statistically significant $(P<0.001)$. Table 3 summarizes these data.

Table 4 shows the MDA and TAC levels for the cervical cancer group by stage of disease. There was a trend toward lower total antioxidant capacity as stage increased, but this was not statistically significant $(P=0.06)$. Similarly, there was a trend toward a higher MDA level with stage $(P=0.07)$.

Table 3 Comparison of oxidative stress index (OSI) for women with cervical cancer versus women without cervical cancer (Control)

\begin{tabular}{lc}
\hline & $\begin{array}{l}\text { Oxidative stress index }(\mathrm{OSI}) \\
\text { Mean } \pm \mathrm{SD}\end{array}$ \\
\hline Cervical cancer $(N=50)$ & $0.83 \pm 0.31$ \\
Control $(N=50)$ & $0.19 \pm 0.04$ \\
$P$ value & $<0.001$ \\
\hline
\end{tabular}

\section{Discussion}

DNA damage through oxidation has been associated with carcinogenesis through the development of oxidizing reactive molecules. These molecular insults may have carcinogenetic effects secondary to the impact on p53, cell proliferation, invasiveness and metastases [26]. The intermediate step is oxidative stress which induces toxicity and damage of protein, lipids and DNA through oxygen free radicals and leads to base damage and DNA strand breaks [27]. While high-risk human papillomavirus infections are the known etiologic agents for the development of cervical cancer, only a small subset of all women infected with HRHPV will go on to develop cervical cancer. Most risk factors for cervical cancer identify the social determinants of disease such as poverty, malnutrition, sexual exposure to HR-HPV through early marriage, high parity and lack of access to healthcare [10]. But the biological and molecular factors that lead to persistent HR-HPV infections are still poorly understood [28]. Alterations in the cervical 
Table 4 Lipid peroxidation (MDA), total antioxidant capacity (TAC) and oxidative stress index (OSI) for women with cervical cancer by FIGO stage

\begin{tabular}{llll}
\hline Stage (FIGO) & MDA & TAC & OSI \\
\hline $\mathrm{N}(\%)$ & Mean $\pm \mathrm{SD}$ & Mean \pm SD & Mean \pm SD \\
$\mathrm{Ib} 3 \mathrm{~N}=7(14 \%)$ & $6.54 \pm 1.93$ & $1017.02 \pm 254.78$ & $0.64 \pm 0.27$ \\
$\mathrm{IIb} \mathrm{N}=19(38 \%)$ & $7.51 \pm 2.126$ & $945.7 \pm 228.04$ & $0.79 \pm 0.28$ \\
$\mathrm{IIIb} \mathrm{N}=24(48 \%)$ & $7.86 \pm 2.22$ & $921 \pm 232.18$ & $0.85 \pm 0.34$ \\
$P$ value & 0.07 & 0.06 & 0.05 \\
\hline
\end{tabular}

FIGO Federation International Gynecology Obstetrics, $M D A$ malondialdehyde-the measure of lipid peroxidation, $O S I$ oxidative stress index, TAC total antioxidant capacity microbiome have been studied to identify other potential localizing cofactors leading to carcinogenesis. In one study, folate biosynthesis and oxidate phosphorylation occurred at higher levels in women with preinvasive and invasive cervical cancer [29]. In vitro analysis of antioxidative factors in cervical cancer cell lines suggests enhancement of cancer cell growth [30]. Our study sought to compare the products of the reactive oxygen speciesinduced lipid peroxidation as an indirect measure of oxidative stress for women with a known diagnosis of cervical cancer compared to those without cervical cancer. We investigated the total antioxidant capacity and lipid peroxidation status in this study population of fifty cases and fifty matched controls. The clinical utility of identifying a difference in total antioxidant capacity is that this information may help identify the subset of women with persistent HPV infections who develop malignant transformation.

In our study, lipid peroxidation in cervical cancer patients was $7.49 \pm 2.13 \mathrm{SD} \mu \mathrm{mol} / \mathrm{L}$ and in the control group it was $3.28 \pm 0.58 \mathrm{SD} \mu \mathrm{mol} / \mathrm{L}$ which was highly significant $(P<0.001)$. This observation was in agreement with the research of Ayala et al. [31]. They noted that plasma MDA levels in cancer patients were $5.23 \pm 2.13$ SD compared to $3.83 \pm 2.23 \mathrm{SD}$ in their controls. Another study showed the average plasma MDA level of $7.23 \mu \mathrm{mol} / \mathrm{L}$ in cancer patients and $5.18 \mu \mathrm{mol} / \mathrm{L}$ in the comparison group. The difference was significant, and this finding is consistent with the present study [32].

In the present study, total antioxidant capacity (TAC) in cervical cancer patients was $972.77 \pm 244.22$ SD $\mu$ mol equivalent to ascorbic acid/L and in the control group it was $1720.13 \pm 150.81 \mathrm{SD} \mu \mathrm{mol}$ equivalent to ascorbic acid/L. The difference was statistically significant $(P<0.001)$. Our results are consistent with the results of other investigations. In another report, the TAC levels in cervical cancer patients and controls were $1320 \pm 0.029$ SD $\mu$ mol Trilox equivalent/L and $1620 \pm 0.042$ SD $\mu \mathrm{mol}$ Trilox equivalent/L, respectively [33]. Subramanyam reported TAC levels in cervical cancer patients and controls as $1000.2 \pm 2.44 \mathrm{SD} \mu \mathrm{mol}$ Trilox equivalent/L and $3100 \pm 1.24$ SD $\mu$ mol Trilox equivalent/L, respectively, which is similar to our findings [34]. In our study, the level of oxidative stress index (OSI) in cervical cancer patients was $0.83 \pm 0.31 \mathrm{SD}$ and in the control group was $0.19 \pm 0.04 \mathrm{SD}$ and the difference was statistically significant $(P<0.001)$. This correlates with other research which found the OSI in cancer patients at $1.72 \pm 0.048$ compared to $1.36 \pm 0.061$ in their control group [35]. In a review of oxidative stress and cancer in general, reactive oxygen species have been shown to modify the activity of antioxidant transcription factors [36]. This information could potentially be harnessed to treat women with antioxidants such as ascorbic acid [37].

Looking at the participants by stage of cervical cancer, there was a trend toward lower total antioxidant capacity, a higher MDA level and higher OSI as stage increased but this was not statistically significant. If variations of OSI with size of cancer can be replicated with larger trials, this may be an interesting prognostic indicator as well.

The present study has some limitations. This is an observational study looking at differences in antioxidant capacity in cases versus controls at one point in time. It may be that this measurement changes over time based on tumor size, recurrence risks, treatment modalities, time from treatment and other associated health factors such as nutritional status. A larger prospective cohort study would be needed to answer these questions. The study was conducted in a single center in Dhaka city. Dhaka is a densely populated city with many environmental pollutants that may influence changes in oxidative stress that may contribute to carcinogenesis [38]. However, the control group without cervical cancer was also recruited from the same environment. The sample size was small, and subtle variations in OSI that might be clinically important such as differences by stage and histopathology could not be identified from these data.

\section{Conclusion}

Our results show that there was a significant increase in lipid peroxidation and a significant impairment of antioxidant status in cervical cancer patients compared to controls 
without cervical cancer. This imbalance leads to significant increase in oxidative stress index (OSI) in cervical cancer patients. Further studies are needed to explore the role of oxidative stress as a cofactor for cervical carcinogenesis.

Acknowledgements Department of Pharmacology, Bangabandhu Sheikh Mujib Medical University, Dhaka, Bangladesh.

Authors Contribution TN and SP provided research concept. TN was the principal investigator. SP was a supervisor. TN and AG performed data curation. AG and SP performed review and editing.

Funding No funding of the project came from industry or government funds. Support for publication comes from an endowed Global Health Fund-Strength \& Serenity MGH 1200020707.

Data Availability Raw data are available upon request.

Code availability Software devised with SPSS for Windows version 23 is available online at https://www.ibm.com/analytics/spss-statis tics-software?p1 $=$ Search\&p4=43700050436265267\&p5=b\&gclid $=C j$ wKCAiAkJKCBhAyEiwAKQBCkvdKnIIgLEq6MeQLm6IIATfPDO V-JrPKIAjtdoz7IXWq3Rvo0WtcQBoClhgQAvD_BwE\&gclsrc=aw.ds

\section{Declarations}

Conflict of interest The authors have no competing interest or conflicts of interest to declare.

Ethical Approval The research protocol was approved by the Ethical Review Committee of NICRH. The certificate of approval is available upon request.

Consent to Participate The aims and objectives of the study along with its procedure, methods, risks and benefits of this study were explained to each participant in easily understandable local language, and written informed consent was taken from each patient.

Consent for Publication All authors have reviewed the manuscript and consent to its publication.

Open Access This article is licensed under a Creative Commons Attribution 4.0 International License, which permits use, sharing, adaptation, distribution and reproduction in any medium or format, as long as you give appropriate credit to the original author(s) and the source, provide a link to the Creative Commons licence, and indicate if changes were made. The images or other third party material in this article are included in the article's Creative Commons licence, unless indicated otherwise in a credit line to the material. If material is not included in the article's Creative Commons licence and your intended use is not permitted by statutory regulation or exceeds the permitted use, you will need to obtain permission directly from the copyright holder. To view a copy of this licence, visit http://creativecommons. org/licenses/by/4.0/.

\section{References}

1. Vu M, Do JY, Awolude AO, Chuang L. Cervical cancer worldwide. Curr Probl Cancer. 2018;45(5):457-65. https://doi.org/10. 1016/j.currproblcancer.2018.06.003.

2. Haque N, Uddin A, Dey BR, Islam F, Goodman A. Challenges to cervical cancer treatment in Bangladesh: the development of a women's cancer ward at Dhaka Medical College Hospital. Gynecol Oncol Rep. 2017;21:67-72. https://doi.org/10.1016/j. gore.2017.06.001.

3. Parkin DM. The global health burden of infection-associated cancers in the year 2002. Int J Cancer. 2006;118(12):3030-44. https://doi.org/10.1002/ijc.21731.

4. Goodman A. HPV testing as a screen for cervical cancer. BMJ. 2015;30(350): h2372. https://doi.org/10.1136/bmj.h2372.

5. Ramanakumar AV, Goncalves O, Richardson $\mathrm{H}$, et al. Human papillomavirus (HPV) types 16, 18, 31, 45 DNA loads and HPV16 integration in persistent and transient infections in young women. BMC Infect Dis. 2010;10:326. https://doi.org/10.1186/ 1471-2334-10-326.

6. Moody CA, Laimins LA. Human papillomavirus oncoproteins: pathways to transformation. Nat Rev Cancer. 2010;10(8):550-60. https://doi.org/10.1038/nrc2886.

7. Hausen HZ. Papillomaviruses in the causation of human cancers: a brief historical account. Virology. 2009;384(2):260-5. https:// doi.org/10.1016/j.virol.2008.11.046.

8. Williams VM, Filippova M, Soto U, Duerksen-Hughes PJ. HPVDNA integration and carcinogenesis: putative roles for inflammation and oxidative stress. Future Virol. 2011;6(1):45-57. https://doi.org/10.2217/fvl.10.73.

9. Moreno V, Bosch FX, Muñoz N, Meijer CJ, Shah KV, Walboomers JM, Herrero R, Franceschi S, International Agency for Research on Cancer. Multicentric Cervical Cancer Study Group. Effect of oral contraceptives on risk of cervical cancer in women with human papillomavirus infection: the IARC multicentric case-control study. Lancet. 2002;359:1085-92. https://doi.org/10. 1016/S0140-6736(02)08150-3.

10. Torres-Poveda K, Ruiz-Fraga I, Madrid-Marina V, Chavez M, Richardson V. High risk HPV infection prevalence and associated cofactors: a population-based study in female ISSSTE beneficiaries attending the HPV screening and early detection of cervical cancer program. BMC Cancer. 2019;19(1):1205. https://doi. org/10.1186/s12885-019-6388-4.PMID:31823749;PMCID: PMC6905062.

11. Zeng XT, Xiong PA, Wang F, Li CY, Yao J, Guo Y. Passive smoking and cervical cancer risk: a meta-analysis based on 3,230 cases and 2,982 controls. Asian Pac J Cancer Prev. 2012;13(6):2687-93. https://doi.org/10.7314/apjcp.2012.13.6. 2687.

12. Federico A, Morgillo F, Tuccillo C, Ciardiello F, Loguercio C. Chronic inflammation and oxidative stress in human carcinogenesis. Int J Cancer. 2007;121(11):2381-6. https://doi.org/10. 1002/ijc.23192.

13. Patel BP, Rawal UM, Rawal RM, Shukla SN, Patel PS. Tobacco, antioxidant enzymes, oxidative stress, and genetic susceptibility in oral cancer. Am J Clin Oncol. 2008;31(5):454-9. https://doi. org/10.1097/COC.0b013e31816a61da.

14. Klaunig JE, Xu Y, Isenberg JS, Bachowski S, Kolaja KL, Jiang J, Stevenson DE, Walborg EF Jr. The role of oxidative stress in chemical carcinogenesis. Environ Health Persp. 1998;106(Suppl 1):289-95. https://doi.org/10.1289/ehp.98106s1289.

15. Pryor WA, Godber SS. Noninvasive measures of oxidative stress status in humans. Free Radic Biol Med. 1991;10(3-4):177-84. https://doi.org/10.1016/0891-5849(91)90073-c.

16. Samir M, el Kholy NM. Thiobarbituric acid reactive substances in patients with laryngeal cancer. Clin Otolaryngol Allied Sci. 1999;24(3):232-4. https://doi.org/10.1046/j.1365-2273.1999. 00249.x.

17. Ghiselli A, Serafini M, Natella F, Scaccini C. Total antioxidant capacity as a tool to assess redox status: critical view and experimental data. Free Radic Biol Med. 2000;29(11):1106-14. https://doi.org/10.1016/s0891-5849(00)00394-4. 
18. Palinkas LA, Horwitz SM, Green CA, Wisdom JP, Duan N, Hoagwood K. Purposeful sampling for qualitative data collection and analysis in mixed method implementation research. Adm Policy Ment Health. 2015;42(5):533-44. https://doi.org/10.1007/ s10488-013-0528-y.

19. Quinn KM, Kartikasari AER, Cooke RE, Koldej RM, Ritchie DS, Plebanski M. Impact of age-, cancer-, and treatment-driven inflammation on $\mathrm{T}$ cell function and immunotherapy. J Leukoc Biol. 2020;108(3):953-65. https://doi.org/10.1002/JLB. 5MR0520-466R.

20. Benzie IF, Strain JJ. Ferric reducing/antioxidant power assay: direct measure of total antioxidant activity of biological fluids and modified version for simultaneous measurement of total antioxidant power and ascorbic acid concentration. Methods Enzymol. 1999;299:15-27. https://doi.org/10.1016/s00766879(99)99005-5.

21. Das BS, Thurnham DI, Patnaik JK, Das DB, Satpathy R, Bose TK. Increased plasma lipid peroxidation in riboflavin-deficient, malaria-infected children. Am J Clin Nutr. 1990;51(5):859-63. https://doi.org/10.1093/ajen/51.5.859.

22. Afroj S, Banu M, Sultana S, Jahan R, Rahman S, Begum N. Clinicopathological profile of cervical cancer patients attending in a specialized hospital. J Dhaka Med College. 2018;26(2):117-21. https://doi.org/10.3329/jdmc.v26i2.38826.

23. Fujita M, Tase T, Kakugawa Y, Hoshi S, Nishino Y, Nagase S, Ito $\mathrm{K}$, Niikura $\mathrm{H}$, Yaegashi N, Minami Y. Smoking, earlier menarche and low parity as independent risk factors for gynecologic cancers in Japanese: a case-control study. Tohoku J Exp Med. 2008;216(4):297-307. https://doi.org/10.1620/tjem.216. 297.

24. Thulaseedharan JV, Malila N, Hakama M, Esmy PO, Cheriyan M, Swaminathan R, Muwonge R, Sankaranarayanan R. Socio demographic and reproductive risk factors for cervical cancer: a large prospective cohort study from rural India. Asian Pac J Cancer Prev. 2012;13(6):2991-5. https://doi.org/10.7314/apjcp. 2012.13.6.2991.

25. Vanakankovit N, Taneepanichskul S. Effect of oral contraceptives on risk of cervical cancer. J Med Assoc Thailand Chotmaihet Thangphaet. 2008;91(1):7-12.

26. Halliwell B. Oxidative stress and cancer: have we moved forward? Biochem J. 2007;401(1):1-11. https://doi.org/10.1042/ BJ20061131.

27. Lennon SV, Martin SJ, Cotter TG. Dose-dependent induction of apoptosis in human tumour cell lines by widely diverging stimuli. Cell Prolif. 1991;24(2):203-14. https://doi.org/10.1111/j.13652184.1991.tb01150.x.
28. Bodily J, Laimins LA. Persistence of human papillomavirus infection: keys to malignant progression. Trends Microbiol. 2011;19(1):33-9. https://doi.org/10.1016/j.tim.2010.10.002.

29. Tango CN, Seo SS, Kwon M, Lee DO, Chang HK, Kim MK. Taxonomic and functional differences in cervical microbiome associated with cervical cancer development. Sci Rep. 2020;10(1):9720. https://doi.org/10.1038/s41598-020-66607-4.

30. Wang M, Xue Y, Shen L, Qin P, Sang X, Tao Z, Yi J, Wang J, Liu P, Cheng $\mathrm{H}$. Inhibition of SGK1 confers vulnerability to redox dysregulation in cervical cancer. Redox Biol. 2019;24: 101225. https://doi.org/10.1016/j.redox.2019.101225.

31. Ayala A, Muñoz MF, Argüelles S. Lipid peroxidation: production, metabolism, and signaling mechanisms of malondialdehyde and 4-hydroxy-2-nonenal. Oxid Med Cell Longev. 2014;2014:360-438. https://doi.org/10.1155/2014/360438.

32. Manoharan S, Kolanjiappan K, Kayalvizhi M, Sethupathy S. Lipid peroxidation and antioxidant status in cervical cancer patients. J Biochem Mol Biol Biophys. 2002;6(3):225-7. https:// doi.org/10.1080/10258140290018685.

33. Shah S, Kalal BS. Oxidative stress in cervical cancer and its response to chemoradiation. Turk $\mathrm{J}$ Obstet Gynecol. 2019;16(2):124-8. https://doi.org/10.4274/tjod.galenos.2019. 19577.

34. Subramanyam D, Subbaiah KV, Rajendra W, Lokanatha V. Serum selenium concentration and antioxidant activity in cervical cancer patients before and after treatment. Exp Oncol. 2013;35(2):97-100.

35. Genet S, Gamini M, El Metwally TH. Deranged antioxidant status and oxidative stress in patients with cervical cancer receiving radiotherapy. React Oxygen Species. 2018;5(13):68-77. https://doi.org/10.20455/ros.2018.807.

36. Hayes JD, Dinkova-Kostova AT, Tew KD. Oxidative stress in cancer. Cancer Cell. 2020;38(2):167-97. https://doi.org/10.1016/ j.ccell.2020.06.001.

37. Goodman A. Vitamin C and cancer. AIMS Med Sci. 2016;3(1):41-51. https://doi.org/10.3934/medsci.2016.1.41.

38. Franco R, Panayiotidis MI. Environmental toxicity, oxidative stress, human disease and the "black box" of their synergism: how much have we revealed? Mutat Res. 2009;674(1-2):1-2. https://doi.org/10.1016/j.mrgentox.2009.01.005.

Publisher's Note Springer Nature remains neutral with regard to jurisdictional claims in published maps and institutional affiliations. 